\title{
Efeitos de diferentes sistemas de acondicionamento ambiente sobre o desempenho produtivo de frangos de corte
}

\author{
Dermeval A. Furtado ${ }^{1}$, Renilson T. Dantas ${ }^{2}$, José W. B. do Nascimento ${ }^{1}$, José T. Santos ${ }^{3}$ \& Fernando G. P. Costa ${ }^{4}$
}

\begin{abstract}
RESUMO
O principal objetivo deste trabalho foi avaliar a influência ambiental nos índices de conforto térmico e produtivo, em instalações abertas de frangos de corte, cobertos com telha de cimento amianto, com três sistemas de acondicionamento térmico: ventilação artificial e aspersão sobre a cobertura (TAVA), ventilação artificial (TACV) e ventilação artificial e nebulização (TAVN), localizados no distrito de São José da Mata, município de Campina Grande, PB. A avaliação ambiental foi feita com base na umidade relativa do ar (UR), no índice de temperatura do globo negro e umidade (ITGU), na carga térmica radiante (CTR) e pela umidade da cama. Os índices produtivos foram avaliados pelo peso final, ganho de peso diário, conversão alimentar e taxa de mortalidade. Em todos os sistemas, os índices de conforto variaram ao longo do dia, sendo que o ITGU apresentou valores considerados acima do ideal e a UR e a CTR ficaram dentro da zona de conforto térmico recomendada. O sistema TAVN aumentou a umidade da cama em relação aos outros sistemas. Os valores dos índices de desempenho das aves estiveram dentre as faixas consideradas ideais para a indústria de frangos de corte, no Nordeste do Brasil.
\end{abstract}

Palavras-chave: avicultura, conforto térmico, ambiência

\section{Effect of different environment conditioning systems on the productive performance of chickens}

\begin{abstract}
The principal objective of this work was to evaluate the environmental influence on the thermal comfort and productive indices, in poultry farm installations, covered with cement asbestos tiles using three diferent thermal air conditioning systems: artificial ventilation and water sprinkling over the roof, artificial ventilation and artificial ventilation and humidification. The poultry farm is located in the district of São José da Mata, in the municipality of Campina Grande, Paraiba state, Brazil. The environmental evaluation was based on the relative humidity of the air, black globe temperature and humidity index, thermal radiation load, and humidity of the bed. The production indices were evaluated through the final weight, daily weight gain, feed conversion and mortality rate. In all systems the comfort indices varied during the day. Black globe temperature and humidity index presented above ideal values. Relative humidity and thermal radiation load indices were within the recommended thermal comfort zone. Artificial ventilation and humidification systems increased the humidity of the bed when compared to the other systems. The values of the poultry performance indices were within the ideal range considered for the broiler industry in the Northeast of Brazil.
\end{abstract}

Key words: chickens, thermal comfort, environment

${ }^{1}$ DEAg/UFCG. Av. Aprígio Veloso 882, CEP: 58109-970, Campina Grande, PB. Fone: (83) 33101486 E-mail: dermeval@deag.ufcg.edu.br e wallace@deag.ufcg.edu.br 2 DCA/UFCG. Fone: (83) 3310 1201. E-mail: renilson@dca.ufcg.edu.br

${ }^{3}$ Rua do Sol 310, CEP: 58397-000, Areia, PB. Fone: (83) 33622638

${ }^{4}$ DZ/UFPB, Campus Universitário. CEP: 58397-000, Areia, PB. Fone: (83) 3362 2504. E-mail: fperazzo@cca.ufpb.br 


\section{INTRODUÇÃO}

A avicultura é a atividade que possui o maior acervo tecnológico, no setor agropecuário brasileiro. Os grandes progressos em genética, nutrição, manejo e sanidade, verificados nos últimos anos, transformaram a atividade num verdadeiro complexo econômico, traduzido por grande indústria de produção de proteína de origem animal (Tinôco, 1998). Apesar do enorme crescimento da avicultura verifica-se que, em climas tropicais e subtropicais, a exemplo do Brasil, os altos valores da temperatura e da umidade relativa do ar, principalmente na primavera e no verão, geram condições de desconforto térmico quase permanente, às aves, inibindo o seu desempenho produtivo e se constituindo em um dos principais problemas que afetam a sua criação (Fonseca, 1998).

Segundo Tinôco (2001) as aves realizam suas atividades de mantença e produção gerando certa quantidade de calor necessitando, para desenvolver sua atividade vital, de um desnível térmico em relação ao meio externo, cuja temperatura ambiente das instalações deve estar na faixa de conforto, para que ele atinja o seu potencial genético. De acordo com Silva (2000) quando o ambiente onde os animais estão sendo criados, se torna desconfortável, estes intensificam os mecanismos de conservação ou dissipação de calor, para manter a sua homeotermia. Buffington et al. (1983) relataram que no estado de estresse calórico, além da ingestão de alimentos ser reduzida, o animal gasta parte dessa energia alimentar no processo de dissipação do calor que, na ausência do estresse, estaria disponível para a produção.

A zona de termoneutralidade está relacionada a um ambiente térmico ideal, no qual as aves encontram condições perfeitas para expressar suas melhores características produtivas. Baêta \& Souza (1997) e Tinôco (2001) consideraram ambiente confortável aquele com temperaturas entre 18 a $28^{\circ} \mathrm{C}$ e umidade relativa ente 50 e $70 \%$. Teixeira (1983) concluiu que ambientes cujos valores de ITGU variaram entre 65,0 e 77,0, não afetaram o desempenho dos frangos de corte. Em trabalho realizado por Rosa (1984) foram obtidos, em Viçosa, MG, às $14 \mathrm{~h}$, com céu claro e 12,3 h de insolação, CTR de $515,4 \mathrm{~W} \mathrm{~m}^{-2}$ para galpões com telhas de cimento amianto, e 498,3 $\mathrm{W} \mathrm{m}^{-2}$ para galpões com telhas de barro (francesa).

Alguns fatores devem ser levados em consideração quanto à utilização da cama para criação de frangos de corte, podendo-se citar o tipo de material utilizado, através do qual verifica a capacidade de absorção que este apresenta; a disponibilidade do material e o valor nutritivo que o material mostra para outras espécies animais. Segundo Ângelo et al. (1997) vários são os materiais que podem ser utilizados como cama de aviário, como a casca de arroz, o bagaço de cana e feno de leguminosas e gramíneas.

A avaliação do desempenho produtivo das aves em relação às condições ambientais oferecidas, é realizada através de análises dos índices zootécnicos, como: consumo de ração (CR) das aves, ganho de peso semanal (GP) ou diário (GPD), conversão alimentar (CA), peso vivo médio sema- nal (PV) e taxa de mortalidade (TM). Fabrício (1994) encontrou, em experimentos com frangos de corte, um GPD de 54,63 e 53,8 $\mathrm{g} \mathrm{d}^{-1}$, uma CA de 2,07 e 2,01 e uma TM de 5,82 e 5,01, para galpões com e sem nebulizadores, respectivamente. Vieira et al. (2003) pesquisando dois galpões na região de Campina Grande, PB, com telha de cimento amianto, ventilação artificial, com e sem pintura na face externa, encontraram valores de PV de 2,49 e 2,55 kg; GPD de 52,97 e 53,12 g por ave; CA de 1,92 e 1,87 e TM de 2,5 e $2,72 \%$, respectivamente.

Objetivou-se, através do presente trabalho, avaliar a influência ambiental em instalações de frangos de corte, cobertos com telha de cimento amianto, com três sistemas de acondicionamento térmico, ou seja: ventilação artificial e aspersão sobre a cobertura, ventilação artificial e ventilação artificial e nebulização, correlacionando-os com os índices produtivos.

\section{MATERIAL E MÉTODOS}

Este trabalho teve sua fase experimental realizada em três galpões de criação comercial de frangos de corte na granja Santíssimo, situada no Município de Campina Grande, PB ( $07^{\circ} 12^{\prime} \mathrm{S}$ de latitude; $35^{\circ} 52^{\prime} \mathrm{W}$ e $502 \mathrm{~m}$ de altitude). O experimento foi conduzido nos meses de novembro e dezembro de 2001, utilizando-se um lote de sexo misto de 13.200 aves, com peso inicial médio de $47 \mathrm{~g} \mathrm{ave}^{-1}$, da linhagem COBB, em que cada galpão tinha 4.400 aves e densidade de 10,4 aves $\mathrm{m}^{-2}$. O período experimental foi realizado dos 19 aos 48 dias de idade das aves.

\section{Caracterização dos aviários}

Todos os galpões estavam orientados no sentido LesteOeste, não possuíam lanternins, seu piso era concretado, laterais protegidas com telas de arame galvanizado, cortinas manuais, cama com $10 \mathrm{~cm}$ de espessura composta de bagaço de cana-de-açúcar e de palha de arroz. Os galpões tinham $47 \mathrm{~m}$ de comprimento por $9 \mathrm{~m}$ de largura; pé-direito com $3,0 \mathrm{~m}$; beirais com $1,50 \mathrm{~m}$; os oitões eram formados de parede de alvenaria, semi-abertos e pintados de branco; muretas com 0,46 m de altura. A cobertura dos galpões se compunha de telha de amianto, com espessura de $0,004 \mathrm{~m}$, apoiada em duas águas, dispostos no sentido transversal do galpão. Os comedouros eram automáticos e os bebedouros pendulares. A distância entre os galpões era de $40 \mathrm{~m}$ e, entre os galpões, existia uma cobertura com grama.

Todos os galpões dispunham de sistema de ventilação artificial, composto por quatro ventiladores helicoidais, que eram acionados quando a temperatura do ar atingia $25^{\circ} \mathrm{C}$. No galpão 1 foi implantado o sistema de aspersão de água sobre a cobertura (TAVA), constituído de dois tubos de polietileno, um em cada lateral do telhado, nos quais foram introduzidos os aspersores. No galpão 2 utilizou-se apenas o sistema de ventilação (TACV) e, no galpão 3, o sistema de nebulização (TAVN), formado de duas linhas eqüidistantes, nos quais se localizavam os 
nebulizadores, com distância de $2 \mathrm{~m}$ entre os bicos, distribuídos ao longo do galpão e fixados a uma altura de $3,0 \mathrm{~m}$, que entravam em funcionamento quando a temperatura do ar era superior a $29{ }^{\circ} \mathrm{C}$, e desligados quando a umidade relativa do ar alcançava $80 \%$ ou quando se presenciava condensação sobre a cama.

\section{Medição das variáveis ambientais e produtivas}

No interior do galpão, as leituras foram feitas durante trinta dias, a cada $2 \mathrm{~h}$, no intervalo das 6 às $16 \mathrm{~h}$, realizando-se as seguintes medições: temperatura de bulbo seco, bulbo úmido, globo negro, todos com resolução de $0,1{ }^{\circ} \mathrm{C}$ e velocidade do vento, realizadas a $0,35 \mathrm{~m}$ acima do nível da cama, correspondendo ao centro de massa das aves. No exterior dos galpões obteve-se a temperatura externa, através de um abrigo meteorológico, no interior do qual ficaram os termômetros de bulbo seco e de bulbo úmido e, externamente, o termômetro de globo negro, fixado na extremidade do abrigo, ou seja, em contato direto com a irradiação solar. Com esses dados, foram encontrados, tanto no interior dos galpões quanto na área externa, os valores da umidade relativa do ar (UR), do índice de temperatura do globo negro e umidade (ITGU) e da carga térmica de radiação (CTR), nos horários considerados.

O ITGU foi calculado utilizando-se a equação proposta por Buffington et al. (1977):

$$
\text { ITGU }=\text { Tgn }+0,36 \text { Tpo }-330,08
$$

em que:

Tgn - temperatura do globo negro, $\mathrm{K}$

Tpo - temperatura do ponto de orvalho, $\mathrm{K}$

Os valores da CTR foram obtidos utilizando-se a equação proposta por Esmay (1969):

$$
\mathrm{CTR}=\mathrm{O}^{\prime}(\mathrm{TRM})^{4}
$$

em que:

$$
\begin{aligned}
& \text { CTR - carga térmica radiante, } \mathrm{W} \mathrm{m}^{-2} \\
& \text { Ơ - constante de Stefan-Boltzmann, }(5,67 \mathrm{x} \\
& \left.\quad 10^{-8} \mathrm{~W} \mathrm{~m}^{-2} \mathrm{~K}^{-4}\right)
\end{aligned}
$$

$\mathrm{TRM}$ - temperatura radiante média, $\mathrm{K}$

A temperatura radiante média (TRM) descrita por Bond et al. (1954) pode ser expressa pela equação:

$$
\mathrm{TRM}=100\left[2,51 \cdot \mathrm{v}^{1 / 2} \cdot(\text { Tgn-Tbs })+(\operatorname{Tgn} / 100)^{4}\right]^{1 / 4}
$$

em que:

$$
\begin{aligned}
& \text { Tbs - temperatura do ar, } \mathrm{K} \\
& \mathrm{v} \text { - velocidade do vento, } \mathrm{m} \mathrm{s}^{-1}
\end{aligned}
$$

Para determinar a umidade da cama em percentagem foram colhidas, semanalmente, seis amostras de cada galpão e, em seguida, homogeneizadas (6 amostras) e levadas ao Laboratório de Construções Rurais e Ambiência da Universidade Federal de Campina Grande, e realizada a análise, conforme metodologia descrita por Silva (1990). Para avaliar o desempenho das aves nos três galpões experimentais, utilizaram-se os seguintes índices zootécnicos: peso vivo, ganho de peso diário, conversão alimentar e taxa de mortalidade.

$\mathrm{O}$ experimento foi montado no delineamento em blocos casualizados, com quatro sistemas de acondicionamento térmico (tratamentos), seis horários $(6,8,10,12,14$ e 16 h) e três repetições. Os índices ambientais foram analisados mediante o teste de Tukey a 5\% e a umidade da cama e os índices produtivos mediante o teste " $\mathrm{t}$ " de Student, conforme recomendações de Ferreira (1996).

\section{RESULTADOS E DISCUSSÃO}

\section{Umidade relativa do ar (UR)}

Os resultados médios diários internos e externos da umidade relativa do ar encontram-se relacionados na Tabela 1A, na qual se verifica diferença significativa $(P<0,05)$ na umidade relativa do ar, entre os sistemas de acondicionamento ambiental, em alguns horários de observação. Às 6 e 8 h, os sistemas de acondicionamento não apresentaram diferença significativa, fato este justificado, visto que os sistemas se achavam desligados ou entrando em funcionamento. A UR externa indicou umidade mais elevada, diferindo estatisticamente dos três sistemas de acondicionamento. Observa-se, também que, no horário das $6 \mathrm{~h}$, os sistemas apresentaram uma UR considerada acima do desejável ao ambiente que, segundo as recomendações, deve ficar entre 50 e $70 \%$ (Baêta \& Souza, 1997 e Tinôco, 2001).

No horário das 10 h e 16 h os valores da UR não diferiram entre os sistemas nem entre estes e o exterior. Apenas no horário das 12 e 14 h, o sistema TAVN diferiu estatisticamente dos demais, apresentando valeres de umidades mais elevados. Esta maior umidade relativa pode ser justificada

\begin{tabular}{|c|c|c|c|c|c|c|}
\hline \multirow{2}{*}{ Sistema } & \multicolumn{6}{|c|}{ Horários } \\
\hline & $6: 00$ & $8: 00$ & 10:00 & $12: 00$ & $14: 00$ & $16: 00$ \\
\hline \multicolumn{7}{|c|}{ A. Umidade relativa do ar (\%) } \\
\hline TAVA & 85,9 a & $65,9 \mathrm{a}$ & $54,8 \mathrm{a}$ & $47,3 \mathrm{a}$ & 48,9 a & 57,4 a \\
\hline TACV & 88,4 a & 68,0 a & $56,4 \mathrm{a}$ & 48,6 a & 50,3 a & 59,8 a \\
\hline TAVN & 88,0 a & $68,9 \mathrm{a}$ & $57,3 \mathrm{a}$ & $51,7 \mathrm{~b}$ & $52,8 \mathrm{~b}$ & $60,4 \mathrm{a}$ \\
\hline EXT. & $93,8 \mathrm{~b}$ & $73,5 \mathrm{~b}$ & 56,0 a & 47,9 a & 49,0 a & $58,0 \mathrm{a}$ \\
\hline \multicolumn{7}{|c|}{ B. Índice de temperatura do globo negro e umidade } \\
\hline TAVA & 72,3 a & $76,0 \mathrm{a}$ & $78,9 \mathrm{a}$ & 80,8 a & 80,0 a & $77,1 \mathrm{a}$ \\
\hline TACV & $71,5 \mathrm{a}$ & $75,7 \mathrm{a}$ & 78,9 a & $80,7 \mathrm{a}$ & $80,1 \mathrm{a}$ & $77,1 \mathrm{a}$ \\
\hline TAVN & $71,7 \mathrm{a}$ & $76,1 \mathrm{a}$ & $78,9 \mathrm{a}$ & $79,8 \mathrm{a}$ & $79,4 \mathrm{a}$ & $76,5 \mathrm{a}$ \\
\hline EXT. & $71,4 \mathrm{a}$ & 80,9 b & 85,5 b & 87,6 b & 85,4 b & $79,8 \mathrm{a}$ \\
\hline \multicolumn{7}{|c|}{ C. Carga térmica de radiação $\left(\mathrm{W} \mathrm{m}^{-2}\right)$} \\
\hline TAVA & $452,7 \mathrm{a}$ & 481,9 a & 503,6 a & 517,3 a & 508,8 a & 485,9 a \\
\hline TACV & 449,5 a & 482,9 a & $510,1 \mathrm{a}$ & 525,3 a & $518,5 \mathrm{a}$ & 491,3 a \\
\hline TAVN & 449,3 a & $485,9 \mathrm{a}$ & $505,1 \mathrm{a}$ & 508,7 b & $505,2 \mathrm{a}$ & 480,2 a \\
\hline EXT. & 508,6 b & $744,1 \mathrm{~b}$ & 796,6 b & $810,7 \mathrm{c}$ & 754,3 b & $633,5 \mathrm{~b}$ \\
\hline
\end{tabular}
pela presença dos nebulizadores, que injetaram água na forma de vapor, elevando a umidade relativa do ar.

Tabela 1. Valores médios da umidade relativa do ar, índice de temperatura de globo negro e umidade e carga térmica de radiação, interna e externa, para os diferentes horários e os sistemas com ventilação artificial e aspersão sobre a cobertura (TAVA), ventilação artificial (TACV) e ventilação artificial e nebulização (TAVN) de Tukey 
Observa-se que, em todos os tratamentos, a umidade relativa do ar média dentro dos aviários esteve, na maioria dos horários pesquisados (entre 8 e $18 \mathrm{~h}$ ), de acordo com o recomendado. Verifica-se, em todos os sistemas, que os valores de UR foram decrescentes até as 12 e 14 h, crescendo a partir deste horário. Esta tendência também foi verificada por Moraes et al. (1999), Zanolla et al. (1999), Matos (2001), Furtado et al. (2003) e Vieira et al. (2003).

\section{Índice de temperatura de globo negro e umidade (ITGU)}

Os resultados médios diários internos e externos do índice de temperatura do globo negro e umidade, encontram-se relacionados na Tabela $1 \mathrm{~B}$, na qual se verifica que não houve diferença significativa $(\mathrm{P}<0,05)$ nos valores de ITGU, para os diferentes sistemas de acondicionamento ambiental, nos diversos horários de observação. Considerando-se que o ITGU com valor de até 77 não influencia no desempenho das aves adultas (Teixeira, 1983), vê-se que no horário das 6 e $8 \mathrm{~h}$ os sistemas de acondicionamento apresentaram valores ITGU dentro do recomendado.

No horário das 10, 12 e 14 h, os valores de ITGU estavam acima do desejável, com os valores registrados mais elevados, demonstrando que nos horários mais quentes do dia, os sistemas de acondicionamento térmico utilizados não foram suficientes para reduzir os valores do ITGU. Em condições de campo, uma parcela significativa de sobreaquecimento advém do próprio calor gerado pelas aves, agravando a situação de desconforto térmico no interior das instalações.

Nota-se que os valores médios de ITGU aumentaram a partir das $10 \mathrm{~h}$, atingindo o máximo entre 12 e $14 \mathrm{~h}$, decrescendo em seguida, até as $16 \mathrm{~h}$. Este comportamento diurno dos valores de ITGU também foi constatado por Rosa (1984), Fonseca (1998), Zanolla et al. (1999), Moraes et al. (1999), Matos (2001), Furtado et al. (2003) e Vieira et al. (2003). Os valores de ITGU atingiram o máximo entre as 12 e 14 h (período mais quente do dia), devido à elevação das temperaturas das vizinhanças do globo negro, principalmente da temperatura do solo aquecido e da superfície inferior da cobertura, que são mais elevados quando a irradiância solar global também o é (Rosa,1984). O aumento da temperatura das secções da vizinhança do globo faz com que ele receba mais calor do ambiente, acarretando elevação da sua temperatura com conseqüente elevação nos valores de ITGU.

Nããs et al. (2001) em experimentos realizados com modelos em escala reduzida encontraram, no horário das 14 h, valores de ITGU também superiores aos recomendados. Sartor et al. (2000), em trabalho realizado com resfriamento evaporativo em instalações para frangos de corte, também observaram, no período entre 12 e $14 \mathrm{~h}$, maior estresse devido ao calor, sendo que o melhor desempenho neste horário foi no sistema com ventilador de alta rotação associado à nebulização, acoplado ao ventilador. Quanto ao ambiente externo vê-se, na Tabela 2, diferença estatística em relação ao ambiente interno, permanecendo mais elevado em todos os horários do dia.

\section{Carga térmica de radiação (CTR)}

Os resultados médios diários internos e externos da car- ga térmica de radiação encontram-se relacionados na Tabela $1 \mathrm{C}$, na qual se verifica que houve diferença significativa $(\mathrm{P}<0,05)$ na $\mathrm{CTR}$, entre o sistema TAVN e os outros sistemas, apenas no horário das $12 \mathrm{~h}$, além de diferença entre os sistemas e o ambiente externo, em todas as horas. Considerando-se como referência os valores indicados por Rosa (1984) para abrigos em que se utilizaram telhas de cimento amianto $\left(\mathrm{CTR}=515,4 \mathrm{~W} \mathrm{~m}^{-2}\right)$, vê-se que em todos os horários os tratamentos apresentaram valores inferiores ou semelhantes a estes.

Os menores e maiores valores de CTR ocorreram às $6 \mathrm{e}$ $16 \mathrm{~h}$ e às $12 \mathrm{e} 14 \mathrm{~h}$, respectivamente. Este comportamento diurno da CTR foi verificado ainda por Rosa (1984), Ferreira et al. (1997), Fonseca (1998), Zanolla et al. (1999), Sartor et al. (2000), Nããs et al. (2001), Matos (2001) e Furtado et al. (2003) explicado pelo fato de que os valores que definem a CTR ocorrem em função da radiação solar que, por sua vez, atinge os valores mais elevados próximos de $12 \mathrm{~h}$, quando o sol se posiciona de forma mais perpendicular ao plano do horizonte local e, também, em função da radiação de ondas longas emitidas pela vizinhança (Fonseca, 1998).

\section{Umidade da cama}

Encontram-se na Tabela 2, os dados referentes à umidade da cama, em que se constata que até a segunda semana houve diferenças significativas no TAVN em relação aos sistemas TAVA e TACV, revelando que o sistema TAVN esteve com umidade superior à dos demais tratamentos. Quando se consideram as médias, também se pode constatar que o sistema TAVN apresentou superioridade significativa da umidade da cama em relação aos demais galpões.

Tabela 2. Umidade da cama ( $80 \%$ de bagaço de cana e $20 \%$ de casca de arroz), produzidas por aves criadas nos sistemas com ventilação artificial e aspersão sobre a cobertura (TAVA), ventilação artificial (TACV) e ventilação artificial e nebulização (TAVN)

\begin{tabular}{cccc}
\hline \multirow{2}{*}{ Idade das aves } & \multicolumn{3}{c}{ Umidade da cama (\%) } \\
\cline { 2 - 4 } Período pré-experimental & TAVA & TACV & TAVN \\
\hline $1^{\text {a }}$ Semana & $30,0 \mathrm{a}$ & $31,1 \mathrm{a}$ & $38,7 \mathrm{~b}$ \\
\hline $2^{\text {a Semana }}$ & $32,0 \mathrm{a}$ & $29,7 \mathrm{a}$ & $40,0 \mathrm{~b}$ \\
$3^{\text {a }}$ Semana & $32,8 \mathrm{a}$ & $31,8 \mathrm{a}$ & $40,4 \mathrm{~b}$ \\
\hline $4^{\text {a Semana }}$ & $32,5 \mathrm{a}$ & $29,2 \mathrm{a}$ & $33,2 \mathrm{a}$ \\
\hline Médias & $36,1 \mathrm{a}$ & $29,3 \mathrm{~b}$ & $37,3 \mathrm{a}$ \\
\hline
\end{tabular}

Letras iguais na mesma linha, revelam não haver diferença significativa a nível de $5 \%$ de probabilidade pelo teste "t" de Student

Fonseca (1998), relata que valores de umidade da cama entre 25 e $35 \%$ são considerados favoráveis à criação de frangos de corte e se verificaram no presente trabalho, percentuais de até $40,35 \%$. Os valores encontrados no sistema TAVN foram superiores aos relatados por Barros et al. (2004) que, utilizando diferentes níveis de sódio na ração, relatam níveis de umidade da cama de 37,1 e $35,4 \%$, para criação de machos e fêmeas, respectivamente.

\section{Índices de desempenho produtivo}

Os valores das variáveis produtivas estão apresentados na 
Tabela 3, na qual se observa que estatisticamente não houve diferença significativa entre os índices de desempenho produtivo, ao nível de 5\% de probabilidade. De maneira geral, pode-se observar que os valores encontrados para os índices produtivos se mantiveram dentro das faixas tidas ideais para a indústria de aves de corte.

Tabela 3. Valores médios dos índices zootécnicos nos sistemas com ventilação artificial e aspersão sobre a cobertura (TAVA), ventilação artificial (TACV) e ventilação artificial e nebulização (TAVN)

\begin{tabular}{lccc}
\hline \multirow{1}{*}{ Parâmetros zootécnicos } & \multicolumn{3}{c}{ Sistema } \\
\cline { 2 - 4 } & TAVA & TACV & TAVN \\
Peso vivo médio das aves $(\mathrm{kg})$ & $2,67 \mathrm{a}$ & $2,65 \mathrm{a}$ & $2,63 \mathrm{a}$ \\
Ganho de peso diário $\left(\mathrm{g} \mathrm{dia}^{-1}\right)$ & $54,7 \mathrm{a}$ & $54,3 \mathrm{a}$ & $53,9 \mathrm{a}$ \\
Conversão alimentar $\left(\mathrm{kg} \mathrm{kg}^{-1}\right)$ & $1,93 \mathrm{a}$ & $1,94 \mathrm{a}$ & $1,92 \mathrm{a}$ \\
Taxa de mortalidade $(\%)$ & $3,0 \mathrm{a}$ & $2,75 \mathrm{a}$ & $2,61 \mathrm{a}$ \\
\hline
\end{tabular}

Letras iguais na mesma linha identificam não haver diferença significativa a nível de $5 \%$ de probabilidade, pelo teste "t" de Student

Infere-se que, o desconforto térmico sofrido pelas aves durante o período entre 10 e $16 \mathrm{~h}$ (Tabela 1$)$, possivelmente tenha levado a redução do apetite e, conseqüentemente, redução na ingestão de alimentos. Contudo, ao final do dia e durante a noite, as condições ambientais foram mais confortáveis para os frangos, favorecendo a ingestão de alimento pelas aves, amenizando a situação de desconforto térmico ocorrido durante o dia, sem comprometimento de suas funções produtivas. Os valores de umidade da cama encontrados no presente experimento não influenciaram nos índices produtivos nem nos ambientais.

\section{CONCLUSÕES}

1. Os valores de umidade relativos do ar e da carga térmica de radiação, dentro dos aviários estiveram, entre as 8 e 18 horas, de acordo com o recomendado.

2. Os valores do índice de temperatura do globo negro e umidade nos horários mais quentes do dia, ficaram acima do recomendado, onde os sistemas de acondicionamento térmico utilizados, não foram suficientes para reduzir estes valores, provocando uma situação de desconforto térmico.

3. O aviário que tinha sistema de nebulização interna apresentou uma umidade da cama mais elevada.

4. Os sistemas de acondicionamento térmico testados não afetaram o desempenho das aves, em comparação com os obtidos pela indústria de frangos de corte..

\section{LITERATURA CITADA}

Ângelo, J. C.; González, E.; Kondo, N.; Anzai, N. H.; Cabral, M. M. Material de cama: qualidade, quantidade e efeito sobre o desempenho de frangos de corte. Revista Brasileira de Zootecnia, Viçosa, v.26, n.1, p.121-130, 1997.
Baêta, F. C.; Souza, C. F. Ambiência em edificações rurais - conforto animal, Viçosa: UFV. 1997, 246p.

Barros, J. M. S.; Gomes, P. C.; Albino, L. F. T.; Rostagno, H. S.; Costa, L. F. Exigência de sódio para frangos de corte nas fases de crescimento (22 a 42 dias) e final (43 a 53 dias). Revista Brasileira de Zootecnia, Viçosa, v.33, nº.6, p.17211733, 2004.

Bond, T. E., Kelly, C. F.: Ittner, N. R. Radiation studies of painted shade materials. Transaction of the ASAE. St. Joseph, v.35, n.6, p.389-392,1954.

Buffington, C. S.; Collazo-Arocho, A.; Canton, G. H.; Pitt, D.; Thatcher, W. W.; Collier, R. J. Black globe humidity comfort index for dairy cows. St. Joseph: Transactions of the ASAE, Paper, 77- 4517, 1977. 19p.

Buffington, D. E.; Collier, R. L.; Canton, G. H. Shade manegement system heat stress for dairy cows in hot, humid climates. Transactions of the ASAE, St. Joseph, v.26, n.6, p.1798-1802, 1983.

Esmay, M. L. Principles of animal environment. 2. ed. Westport:CT Abi, 1969, 325p.

Fabrício, J. R. Influência do estresse calórico no rendimento da criação de frango de corte. In: Conferência Apinco de Ciência e Tecnologia Avícola, 1994, São Paulo, Anais... São Paulo: APINCO, 1994. p.129-133.

Ferreira, J. H.; Baêta, F. C.; Baião, N. C.; Soares, P. R.; Cecon, P. C. Posicionamento de ventiladores em galpões para frangos de corte. Engenharia na Agricultura, Viçosa. v.5, n.1, p.43-62, 1997.

Ferreira, P. V. Estatística experimental aplicada à agronomia, 2 ed. Maceió: Editora Universitária, 1996, 604p.

Fonseca, J. M. Efeito da densidade de alojamento sobre o desempenho de frangos de corte criados em sistemas de nebulização e ventilação em túnel. Viçosa: UFV, 1998. 57p. Dissertação Mestrado.

Furtado, D. A.; Azevedo, P. V.; Tinôco, I. F. F. Análise do Conforto térmico em galpões avícolas com diferentes sistemas de acondicionamento. Revista Brasileira de Engenharia Agrícola e Ambiental, Campina Grande, v.7, n.3, p.559-564, 2003.

Matos, M. L. Conforto térmico ambiente e desempenho de frangos de corte, alojados em dois níveis de alta densidade, em galpões com sistemas de ventilação em túnel e ventilação lateral. Viçosa: UFV, 2001. 89p. Dissertação Mestrado.

Moraes, S. R. P.; Tinôco, I. F. F.; Baêta, F. C.; Cecon, P. C. Conforto térmico em galpões avícolas, sob coberturas de cimento amianto e suas diferentes associações. Revista Brasileira de Engenharia Agrícola e Ambiental, Campina Grande, v.3, n.1, p.89-92, 1999.

Nããs, I. A.; Sevegnani, K. B.; Marcheto, F. G.; Espelho, J. C. C.; Menegassi, V.; Silva, I. J. O. Avaliação térmica de telhas de composição de celulose e betumem, pintadas de branco, em modelos de aviários com escala reduzida. Engenharia Agrícola, Jaboticabal, v.21, n.2, p.121-126, 2001.

Rosa, Y. B. C. J. Influência de três materiais de cobertura no índice de conforto térmico em condições de verão, para Viçosa. Viçosa: UFV, 1984. 77p. Dissertação Mestrado.

Sartor, V.; Baeta, F. C.; Orlando, R. C.; Luz, M. L.; Tinôco, I. F. F. Efeito de sistemas de resfriamento evaporativo em instalações para frangos de corte. Engenharia Agrícola, Jaboticabal, v.20, n.2, p.87-97, 2000. 
Silva, D. J. Análise de alimentos: métodos químicos e biológicos. Viçosa: UFV, 1990, 165p.

Silva, R. G. Introdução a bioclimatologia animal. São Paulo: Nobel, 2000. 284p.

Teixeira, V. H. Estudo dos índices de conforto em duas instalações de frango de corte para as regiões de Viçosa e Visconde do Rio Branco, MG. Viçosa: UFV, 1983, 59p. Dissertação Mestrado.

Tinôco, I. F. F. Ambiência e instalações para a avicultura industrial. In: Congresso Brasileiro de Engenharia Agrícola, 27, e Encontro Nacional de Técnicos, Pesquisadores e Educadores de Construções Rurais, 3, Poços de Caldas, Anais... Lavras: UFLA/SBEA, 1998: p.1-86.
Tinôco, I. F. F. Avicultura industrial: novos conceitos de materiais, concepções e técnicas construtivas disponíveis para galpões avícolas brasileiros. Revista Brasileira de Ciência Avícola, Campinas, v.3, n.1, p.1-26, 2001.

Vieira, L. G.; Furtado, D. A.; Nascimento, J. W. B.; Dantas, R. T. Influência da pintura da telha de cimento amianto no desempenho de frangos de corte. In Congresso Brasileiro de Engenharia Agrícola, 32, 2003. Goiânia, Anais... Goiânia: SBEA, 2003. CD-Rom. Zanolla, N.; Tinôco, I. F. F.; Baêta, F. C.; Cecon, P. R. Moraes, S. R. P. Sistemas de ventilação em túnel e lateral na criação de frangos de corte em alta densidade. Revista Brasileira de Engenharia Agrícola e Ambiental, Campina Grande, v.3, n.3, p.361-366, 1999. 